\title{
Pattern and Outcome of Obstetric Admissions into the Intensive Care Unit of a Southeast Nigerian Hospital
}

\author{
Benjamin Chukwuma Ozumba, Leonard Ogbonna Ajah, Vitus Okwuchukwu Obi1, Uche Anthony Umeh, Joseph Tochukwu Enebe ${ }^{2}$, Kingsley Chukwu Obioha ${ }^{3}$ \\ Department of Obstetrics and Gynaecology, Faculty of Medical Sciences, University of Nigeria, ${ }^{2}$ Department of Obstetrics and Gynaecology, ESUT Teaching Hospital, \\ Park Lane, ${ }^{3}$ Department of Obstetrics and Gynaecology, University of Nigeria Teaching Hospital, Ituku-Ozalla, Enugu, ${ }^{1}$ Department of Obstetrics and Gynaecology, \\ Federal Teaching Hospital, Abakaliki, Nigeria
}

\section{Abstract}

Background and Aims: Although pregnancy and labor are considered physiological processes, the potential for catastrophic complications is constant and may develop rapidly. There is growing evidence that admission of high-risk patients into the Intensive Care Unit (ICU) is associated with a reduction in maternal mortality. This study was aimed at reviewing all obstetric patients admitted into the ICU. Materials and Methods: This was a retrospective study of all obstetric patients who were admitted into the ICU between January 1, 2012, and December 31, 2013. Results: There were 89 obstetric patients admitted and managed at the ICU out of 5176 deliveries, thereby accounting for 1 admission in 58 deliveries. Majority of the patients were between 26 and 30 years, primiparous, and unbooked. The indications for ICU admission in this study were ruptured uterus (36.0\%), eclampsia (22.5\%), obstetric hemorrhage (19.1\%), septicemia (10.1\%), severe preeclampsia (6.7\%), and obstructed labor (6.7\%). The maternal and perinatal mortality was $13.5 \%$ and $47.2 \%$, respectively. Maternal unbooked status was significantly associated with maternal mortality $(P<0.05)$. Conclusion: Ruptured uterus was the most common indication for ICU admission in the center. Maternal mortality was significantly associated with unbooked status. This underscores the importance of booking for antenatal care, prompt presentation at the hospital during emergencies, skilled birth attendance, and provision of adequate facilities for the management of critical obstetric cases in this environment.

Keywords: Critical obstetric cases, Intensive Care Unit, obstetric admissions, South-East Nigeria

\section{INTRODUCTION}

Although pregnancy and labor are considered physiological processes, the potential for catastrophic complications is constant and may develop within minutes..$^{[1,2]}$ These complications may be critical and require intensive care. ${ }^{[3]}$ Obstetric patients with these complications are better served by early admission and optimal management in the Intensive Care Unit (ICU) ${ }^{[1-3]}$ Maternal death is still a concern in developing countries despite concerted efforts at eliminating it. ${ }^{[2]}$ To every maternal death, there are about 18 maternal morbidities, and maternal mortality and morbidity are a measure of health-care quality indices in any given community. ${ }^{[2-4]}$ One indicator of pronounced maternal morbidity is obstetric admission into the ICU. ${ }^{[4]}$ Although obstetric admission constitutes a small proportion of admissions into ICUs, the mortality from such admissions is very high. ${ }^{[5]}$ Critically ill obstetric patients account for as much as $1.5 \%-7 \%$ of all ICU admissions in

\begin{tabular}{|l|l|}
\hline \multicolumn{3}{|c|}{ Access this article online } \\
\hline Quick Response Code: & Website: \\
\hline & www.ijccm.org \\
\cline { 2 - 2 } & \\
\hline
\end{tabular}

developing countries. ${ }^{[2,6]}$ There is a growing evidence that admission of high-risk patients to the ICU is associated with a fall in maternal mortality. ${ }^{[7]}$ Management of the critically ill obstetric patients in an ICU is a unique challenge to ICU physicians and obstetricians. ${ }^{[8]}$

Indications for admission to ICU comprise the established causes of acute severe maternal morbidity. Such maternal morbidities also carry very high case fatality rates reflecting the quality of obstetric care available in a given region. ${ }^{[2]}$ Obstetric hemorrhage, eclampsia, septic shock, severe features of preeclampsia, and pulmonary embolism are among the

Address for correspondence: Dr. Leonard Ogbonna Ajah, Department of Obstetrics and Gynaecology, Faculty of Medical Sciences, University of Nigeria, Enugu Campus, Enugu, Nigeria. E-mail: leonard.ajah@unn.edu.ng

This is an open access article distributed under the terms of the Creative Commons Attribution-NonCommercial-ShareAlike 3.0 License, which allows others to remix, tweak, and build upon the work non-commercially, as long as the author is credited and the new creations are licensed under the identical terms.

For reprints contact: reprints@medknow.com

How to cite this article: Ozumba $\mathrm{BC}$, Ajah LO, Obi VO, Umeh UA, Enebe JT, Obioha KC. Pattern and outcome of obstetric admissions into the intensive care unit of a Southeast Nigerian Hospital. Indian J Crit Care Med 2018;22:16-9. 
leading indications for admission into intensive care. ${ }^{[7-12]}$ The unbooked status is a strong risk factor for admission into the ICU, especially in underdeveloped countries where utilization of health facilities is poor. ${ }^{[6]}$ Initial intensive care management includes protecting the airways to maintain patency, breathing adequacy, and maintaining the circulation. Other measures include the use of intravenous fluid, blood transfusion, plasma expanders, antibiotics, control of seizures, and blood pressure. ${ }^{[1]]}$ Oxygen supplementation to improve the oxygen saturation, assisted ventilation, and respiratory support are commonly required. Unfortunately, in a developing economy, quite often patients that require respiratory support do not get it either because of unavailability of ventilators or inability to afford the cost of ICU care. ${ }^{[2,9]}$ The maternal and perinatal mortality in the ICU is significantly higher in under-resourced countries when compared with data from developed countries. ${ }^{[12]}$

Despite a similar profile of obstetric patients admitted to ICUs, the maternal mortality rate in the ICU is significantly higher in under-resourced countries compared to developed countries. ${ }^{[12,13]}$ This is because ICU-admitted patients in under-resourced countries tend to have higher illness severity scores, suggesting delayed admission to the ICU. ${ }^{[12-14]}$ The perinatal mortality associated with maternal critical illness is also significantly higher than in normal parturients who do not have any complications. ${ }^{[12]}$

Ebonyi State has a high maternal mortality ratio mainly due to unbooked status and inadequate or no skilled birth attendance. ${ }^{[15]}$ Therefore, booking the pregnant women would have helped in early detection of high-risk cases and proper surveillance instituted. Among the obstetric patients admitted to the ICU at the Federal Teaching Hospital, Abakaliki (FETHA), this study was carried out to assess their characteristics and peculiarities. It was aimed at determining the pattern and outcome of obstetric admissions to the ICU at FETHA.

\section{Materials and Methods}

\section{Study area}

Abakaliki is the capital of Ebonyi State. Ebonyi State is a mainland southeastern state of Nigeria and has an estimated population of 4.3 million according to the 2006 national census. It occupies a land mass of $5935 \mathrm{~km}^{2}$. Approximately $75 \%$ of the population of Ebonyi State dwell in rural areas with farming as the major occupation. ${ }^{[15]}$ The FETHA is a tertiary hospital located in Abakaliki metropolis. The hospital gets referrals from within Ebonyi State and the neighboring states of Enugu, Abia, Imo, Cross River, and Benue.

\section{Study design}

This was a retrospective study of consecutive obstetric patients that were admitted to the ICU, FETHA from January 1, 2012 to December 31, 2013.

Data were obtained from the patients' case notes and records from the ICU and were entered into a predesigned pro forma.
Analysis was done using Epi Info 7.2.1 (CDC Atlanta Georgia). The Pearson Chi-square test was used for the discrete variables. $P \leq 0.05$ was considered to be statistically significant. Ethical approval was sort and obtained from the Research and Ethics Committee of FETHA.

\section{RESULTS}

A total of 89 obstetric patients out of 5176 deliveries were admitted at the ICU over the 2-year period, thus representing the frequency of $1.7 \%$ or 1 in 58 deliveries. Table 1 summarizes the sociodemographic characteristics of the patients admitted into the ICU. Majority of the patients were between 26 and 30 years, primiparous, and unbooked. Table 2 summarizes the mode of delivery of the patients before admission at the ICU. The most common mode of delivery was laparotomy for ruptured uterus $(36 \%)$.

Table 3 summarizes the indications for admission and the case fatality rate. The most common indication for admission

\begin{tabular}{lc}
\hline \multicolumn{2}{l}{ Table 1: Sociodemographic characteristics of the patients } \\
\hline Parameters & Frequency (\%) \\
\hline Age (years) & \\
$15-20$ & $9(10.1)$ \\
$21-25$ & $24(27.0)$ \\
$26-30$ & $29(32.5)$ \\
$31-35$ & $12(13.5)$ \\
$36-40$ & $15(16.9)$ \\
Parity & \\
1 & $33(37.0)$ \\
$2-4$ & $32(36.0)$ \\
$\geq 5$ & $24(27.0)$ \\
Booking status & \\
Booked & $30(33.7)$ \\
Unbooked & $59(66.3)$ \\
\hline
\end{tabular}

Table 2: Mode of delivery of the patients before admission into the Intensive Care Unit

\begin{tabular}{lc}
\hline Parameters & Frequency (\%) \\
\hline Mode of delivery & \\
Laparotomy for ruptured uterus & $32(36.0)$ \\
Cesarean section & $28(31.5)$ \\
Vaginal delivery & $29(32.5)$ \\
\hline
\end{tabular}

Table 3: Indication for admission and the case fatality rate

\begin{tabular}{lcccc}
\hline $\begin{array}{l}\text { Indications for } \\
\text { admission }\end{array}$ & Frequency (\%) & $\begin{array}{c}\text { No } \\
\text { alive }\end{array}$ & $\begin{array}{c}\text { No } \\
\text { died }\end{array}$ & $\begin{array}{c}\text { Case } \\
\text { fatality (\%) }\end{array}$ \\
\hline Ruptured uterus & $32(36.0)$ & 26 & 6 & 18.8 \\
Eclampsia & $20(22.5)$ & 17 & 3 & 15 \\
Obstetric hemorrhage & $16(18.0)$ & 14 & 2 & 12.5 \\
Septicemia & $9(10.1)$ & 8 & 1 & 11.1 \\
Obstructed labor & $6(6.7)$ & 6 & 0 & 0 \\
Severe preeclampsia & $6(6.7)$ & 6 & 0 & 0 \\
\hline
\end{tabular}


in this study was ruptured uterus (36.0\%) with a case fatality rate of $18.8 \%$. Ruptured uterus contributed $50 \%$ of the overall maternal mortality. The other indications for admission were eclampsia $(22.5 \%)$, obstetric hemorrhage $(19.1 \%)$, septicemia $(10.1 \%)$, severe preeclampsia $(6.7 \%)$, and obstructed labor (6.7\%). Table 4 summarizes the maternal and the fetal outcome of patients admitted to the ICU. Most $(86.5 \%)$ of the patients were successfully treated and transferred to the postnatal ward or discharged home. However, there were $12(13.5 \%)$ and $42(47.2 \%)$ maternal and perinatal deaths, respectively.

Table 5 summarizes the interventions offered while on admission in the ICU. All the patients admitted to the ICU received antibiotics, i.e., $89(100 \%)$. The other interventions, though at different proportions, were oxygen supplementation, use of magnesium sulfate, inotropic drugs, and antishock garments. Table 6 summarizes the relationship between maternal sociodemographic characteristics and the maternal outcome. Maternal unbooked status was significant with maternal mortality $(P \leq 0.05)$.

\section{Discussion}

This study showed that the rate of ICU admission was 1 in 58 deliveries. Most (86.5\%) of the patients were successfully treated while there were $13.5 \%$ maternal deaths. The most common indication for admission in this study was ruptured uterus, and it contributed $50 \%$ of the overall maternal mortality. Maternal unbooked status was associated with maternal mortality in this study.

Despite a series of physiological alterations in pregnancy, most women complete pregnancy, labor, and delivery uneventfully, but a few of them develop complications that may require ICU admissions. The rate of obstetric admission to the ICU in this study of $1.7 \%$ is similar to the $1.86 \%$ reported by Eyelade in Ibadan. ${ }^{[13]}$ This is, however, higher than the $0.28 \%$ of deliveries reported by Okafor and Aniebue in Enugu and $0.73 \%$ of deliveries reported by Ebirim and Ojum in Port Harcourt, Nigeria. ${ }^{[6,7]}$ The reason for the differences in the incidence of ICU admissions in different centers might be due to the peculiar indications for admission in such centers. The sociodemographic characteristics of the patients who had ICU admission in this study are essentially similar to the previous reports in low-resource settings. ${ }^{[2,11,13,14]}$

Ruptured uterus being the most common indication for ICU admission in this study is different from other studies where hypertensive disorders or obstetric hemorrhage were the most common indication for admission. ${ }^{[2,6,7,13,16]}$ This could be because most of the patients admitted to ICU in this study were of low socioeconomic status and had poor health-seeking behavior. Thus, this was reflected by the fact that majority of the patients were unbooked for antenatal care. However, this is particularly worrisome as, owing to improved obstetric care, uterine rupture had remarkably been eliminated in most parts of the world. The other indications for admission to the ICU

\begin{tabular}{lc}
\hline Table 4: Maternal and perinatal outcome & \\
\hline Parameters & Frequency (\%) \\
\hline Maternal outcome & \\
Alive & $77(86.5)$ \\
Died & $12(13.5)$ \\
Fetal outcome & \\
Alive & $47(52.8)$ \\
Died & $42(47.2)$ \\
\hline
\end{tabular}

\begin{tabular}{lc}
\hline $\begin{array}{l}\text { Table 5: Interventions received while on admission at the } \\
\text { Intensive Care Unit }\end{array}$ \\
\hline Intervention received while on admission & Number of patients \\
\hline Antibiotics & 89 \\
Oxygen & 73 \\
Blood transfusion & 62 \\
Magnesium sulfate & 26 \\
Ionotropic & 12 \\
Antishock garment & 5 \\
\hline
\end{tabular}

\begin{tabular}{lcccccc}
\hline \multicolumn{6}{l}{ Table 6: The relationship between maternal } \\
Sociodemographic characteristics and maternal outcome \\
\hline Parameters & Total & $\begin{array}{c}\text { No } \\
\text { alive }\end{array}$ & $\begin{array}{c}\text { No } \\
\text { died }\end{array}$ & OR & $\chi^{2}$ & $P$ \\
\hline Age & & & & & & \\
$15-20$ & 9 & 8 & 1 & 1.000 & 0.402 & 0.526 \\
$21-25$ & 24 & 23 & 1 & 2.875 & & \\
$26-30$ & 29 & 25 & 4 & 0.781 & & \\
$31-35$ & 12 & 11 & 1 & 1.375 & & \\
$36-40$ & 15 & 10 & 5 & 0.250 & & \\
Parity & & & & & & \\
1 & 33 & 30 & 3 & 1.000 & 1.496 & 0.222 \\
$1-4$ & 32 & 28 & 4 & 0.700 & & \\
$\geq 5$ & 24 & 19 & 5 & 0.380 & & \\
Booking status & & & & & & \\
Booked & 30 & 29 & 1 & 1.000 & 3.997 & $0.046^{*}$ \\
Unbooked & 59 & 48 & 11 & 0.150 & & \\
Route of delivery & & & & & & \\
Laparotomy & 32 & 28 & 4 & 1.000 & 0.014 & 0.905 \\
Cesarean & 28 & 24 & 4 & 0.857 & & \\
Vaginal & 29 & 25 & 4 & 0.893 & & \\
\hline
\end{tabular}

*Significant. OR: Odds ratio

in this study were similar to the findings in other studies in this environment. ${ }^{[2,6,7,14]}$

The most common mode of delivery being laparotomy for ruptured uterus in this study is owing to the fact that the predominant admission is due to ruptured uterus. The $13.5 \%$ maternal mortality recorded in this study is $<41.4 \%$ and $40.74 \%$ reported in Ile-Ife and Port Harcourt, respectively. ${ }^{[2,6]}$ The low incidence of maternal deaths in this study may be as a result of the admission criteria, as many of these patients would have been managed in a high dependency unit and may not have required intensive care. While on admission, 
all the patients received antibiotics. Oxygen supplementation and blood transfusion were also required in majority of the patients. This may be as a result of the mode of presentation and the clinical indication for admission. Assisted ventilation and respiratory support are sometimes required in the management of critically ill obstetric patients. However, patients that require respiratory support do not get it either because of unavailability of ventilators or inability to afford the cost of ICU care in resource-poor settings. . $2,9,11,12]^{2}$

The maternal mortality being significantly more among the unbooked patients in this study is similar to a previous report in Enugu, Nigeria. ${ }^{[17]}$ Evidently, the maternal mortality rate is influenced by the population characteristics and level of care. ${ }^{[15]}$ The unbooked status and paucity of ventilators in the study center may have contributed to the recorded maternal mortality. This underscores the importance of booking for antenatal care, prompt presentation at the hospital during emergencies, skilled birth attendance, and provision of adequate facilities for the management of critical obstetric cases. The high perinatal mortality recorded in this study is due to the sociodemographic and obstetric factors, and as previously documented, ruptured uterus was the most common cause of maternal and perinatal deaths in this environment. ${ }^{[18]}$ This study was a hospital-based retrospective type in which its findings may not be a true reflection of what was happening in the society.

\section{ConcLusion}

Ruptured uterus was the most common indication for admission to the ICU and contributed $50 \%$ of maternal mortality in this study. Maternal deaths were significantly associated with maternal unbooked status. This underscores the importance of booking for antenatal care, prompt presentation at the hospital during emergencies, skilled birth attendance, and provision of adequate facilities for the management of critical obstetric cases in this environment.

\section{Financial support and sponsorship}

Nil.

\section{Conflicts of interest}

There are no conflicts of interest.

\section{RefERENCES}

1. Dattaray C, Mandal D, Shankar U, Bhattacharya P, Mandal S. Obstetric patients requiring high-dependency unit admission in a tertiary referral centre. Int J Crit Illn Inj Sci 2013;3:31-5.

2. Faponle AF, Adenekan AT. Obstetric admissions into the Intensive Care Unit in a Sub-urban university teaching hospital. Niger J Obestet Gynaecol 2011;6:33-6.

3. Idris SH, Sambo MN, Ibrahim MS. Barriers to utilisation of maternal health services in a semi-urban community in Northern Nigeria: The clients' perspective. Niger Med J 2013;54:27-32.

4. Adeoye IA, Onayade AA, Fatusi AO. Incidence, determinants and perinatal outcomes of near miss maternal morbidity in Ile-Ife Nigeria: A prospective case control study. BMC Pregnancy Childbirth 2013;13:93.

5. Togal T, Yucel N, Gedik E, Gulhas N, Toprak HI, Ersoy MO, et al. Obstetric admissions to the Intensive Care Unit in a tertiary referral hospital. J Crit Care 2010;25:628-33.

6. Ebirim LN, Ojum S. Admissions of obstetric patients in the Intensive Care Unit: A 5 year review. J Med Med Sci 2012;3:741-4.

7. Okafor UV, Aniebue U. Admission pattern and outcome in critical care obstetric patients. Int J Obstet Anesth 2004;13:164-6.

8. Ramachandra Bhat PB, Navada MH, Rao SV, Nagarathna G. Evaluation of obstetric admissions to Intensive Care Unit of a tertiary referral center in coastal India. Indian J Crit Care Med 2013;17:34-7.

9. Okafor UV. Challenges in critical care services in sub-Saharan Africa: Perspectives from Nigeria. Indian J Crit Care Med 2009;13:25-7.

10. Ghike S, Asegaonkar P. Why obstetrics patients are admitted into Intensive Care Units? A retrospective study. J S Asian Fed Obstet Gynaecol 2012;4:90-2.

11. El-Sawaf A, Shehata M. Acute severe obstetric events in critical care medicine department, Cairo university: Nature and outcome. Med J Cairo Univ 2012;80:665-71.

12. Sultan P, Arulkumaran N, Rhodes A. Provision of critical care services for the obstetric population. Best Pract Res Clin Obstet Gynaecol 2013;27:803-9.

13. Eyelade OR, Amanor-Boadu SD, Sanusi AA, Olumole OA, Sotunbi PT, Soyanwo OA, et al. Intensive Care Unit admission during the puerperium in Ibadan. Trop J Obstet Gynaecol 2005;22:56-9.

14. Muhammed Z, Muhammed D, Ibrahim SA. Obstetric admission to the Intensive Care Unit: A seven years review at the Aminu Kano teaching hospital Kano, Nigeria. Borno Med J 2010;7:1-15.

15. Ezegwui H, Onoh R, Ikeako L, Onyebuchi A, Umeora O, Ezeonu P, et al. Investigating maternal mortality in a public teaching hospital, Abakaliki, Ebonyi State, Nigeria. Ann Med Health Sci Res 2013;3:75-80.

16. Selo-Ojeme DO, Omosaiye M, Battacharjee P, Kadir RA. Risk factors for obstetric admissions to the Intensive Care Unit in a tertiary hospital: A case-control study. Arch Gynecol Obstet 2005;272:207-10.

17. Okafor UV, Efetie ER, Amucheazi A. Risk factors for maternal deaths in unplanned obstetric admissions to the Intensive Care Unit-lessons for sub-Saharan Africa. Afr J Reprod Health 2011;15:51-4.

18. Umeora OU, Ejikeme BN, Egwuatu VE. Contribution of ruptured uterus to maternal mortality in rural South Eastern Nigeria. Trop J Obstet Gynaecol 2005;22:184-8. 